\section{Unexpected Appearance of a Biliary Stent after a Prolonged Period}

Endoscopic internal biliary drainage is known to provide effective palliative decompression therapy for malignant and benign biliary obstructions [1,2]. Late complications developing after the insertion of endoprostheses include stent clogging (33\%), cholangitis (15\%), stent migration into the bile duct (3\%), stent migration into the gastrointestinal tract (3\%), fracture of the endoprosthesis (1\%), and perforation (1\%) [2].

A 59-year-old man with a previously diagnosed benign biliary stricture was admitted with symptoms of fever, jaundice, and epigastric pain. His history included endoscopic insertion of a 10-Fr plastic stent into the common bile duct 5 years previously. Duodenoscopy revealed a swollen papilla and another orifice in addition to the original one near to the papilla. The tip of the stent was emerging from this second orifice. When an endoscopic retrograde cholangiopancreatography (ERCP) cannula was inserted through the original orifice, it emerged into the duodenum

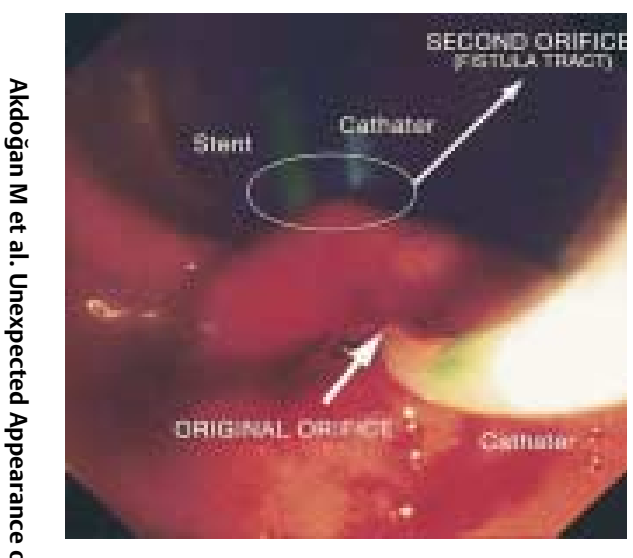

Figure 1 An endoscopic retrograde cholangiopancreatography (ERCP) cannula was inserted into the original orifice and emerged near to the stent from the second orifice. The stent had apparently dislocated into the common bile duct and then perforated the common bile duct through the duodenum to form the second orifice (Figure $\mathbf{1}$ ). We concluded that this new orifice was actually a fistula. When the stent was removed, a large impacted stone was found at its intrabiliary end (Figure $\mathbf{2}$ ).

The simultaneous occurrence of a stone and a fistula may have been caused by the presence of the endoprosthesis for a prolonged period [2]. In summary, this case showed impaction of a stone at the distal end of a long-term plastic stent, resulting in fistula formation and displacement of the distal end of the stent into the duodenum through the fistula.

\section{Akdoğan, B. Kayhan, H. Alkım, B. Şahin}

Dept. of Gastroenterology, Türkiye Yüksek Ihtisas Hospital, Ankara, Turkey

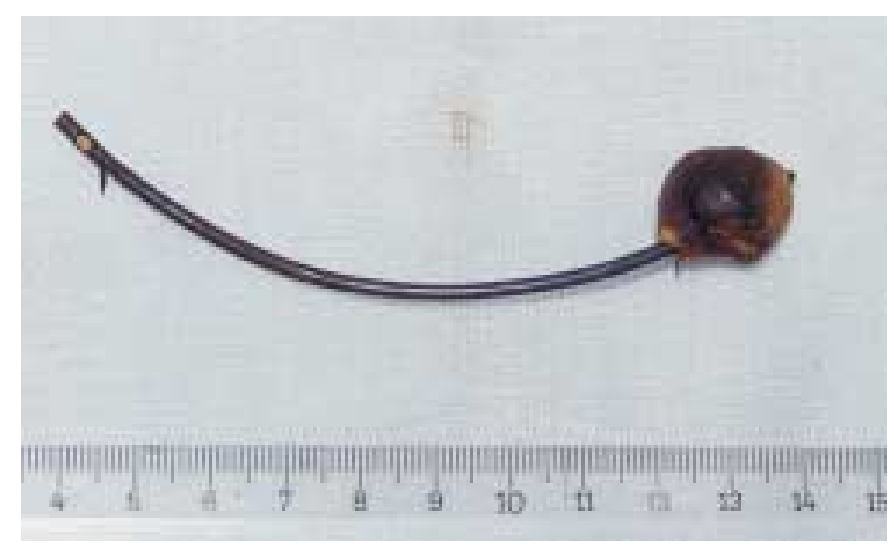

Figure 2 The impacted stone found at the intrabiliary tip of the stent

\section{References}

${ }^{1}$ Mueller PR, Ferruci JT, Teplick SK et al. Biliary stent endoprosthesis: analysis of complications in 113 patients. Radiology 1985; 156: 637-639

${ }^{2}$ Dowidar N, Moesgaard F, Matzen P. Clogging and other complications of endoscopic biliary endoprostheses. Scand J Gastroenterol 1991; 26: 1132-1136

\section{Corresponding Author}

\section{B. Kayhan, M.D.}

Department of Gastroenterology Türkiye Yüksek İhtisas Hospital PK 203

06443 Yenişehir

Ankara

Turkey

E-mail: burkaygastro@hotmail.com 